\title{
Opposite effects of ethanol on electroretinographic ON and OFF responses are due to its action in the distal retina
}

\author{
Aneliya Kuzeva, Sheip Panev, Desislava Zhekova, Petia Kupenova and Elka Popova*
}

*Correspondence: epopova@abv.bg

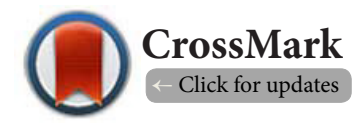

Department of Physiology, Medical Faculty, Medical University of Sofia, 1431 Sofia, Bulgaria.

\begin{abstract}
The aim of the present study was to give insight into the mechanisms of action of ethanol on the function of retinal $\mathrm{ON}$ and $\mathrm{OFF}$ channels. In order to fulfill this aim the effects of ethanol on the electroretinographic (ERG) ON (b-wave) and OFF (d-wave) responses were investigated in intact frog eyecups and in eyecups, where the activity of proximal retinal neurons was blocked by 1 mM N-methyl-D-aspartate (NMDA). Ethanol at all concentrations tested (0.25\%, $0.5 \%$ and 1\%) increased the b-wave amplitude and diminished the d-wave amplitude in the intact eyecups. The time characteristics of the $\mathrm{d}$-wave, but not the b-wave were slowed. Perfusion with NMDA alone also caused significant enhancement of the b-wave amplitude and diminution of the d-wave amplitude. When ethanol was applied in combination with NMDA, its effects on both the b- and d-waves were fully preserved. The results obtained indicate that ethanol effects on the amplitude and time course of the ERG b- and d-waves are due to its action in the distal frog retina. A hypothesis is presented that the opposite effects of ethanol on the b- and d-wave amplitude are due to one and the same mechanism-inhibition of the ionotropic non-NMDA glutamate receptors in retinal horizontal and OFF bipolar cells.
\end{abstract}

Keywords: Ethanol, electroretinogram, retina, NMDA

\section{Introduction}

Acute consumption of ethyl alcohol (ethanol) affects a variety of visual functions, but the site where ethanol exerts its action is largely unknown. Some of ethanol effects may originate in the retina, while others may have their origin in the higher brain visual centers. It has been shown that some ethanol effects in frog retina resemble those of GABA receptor antagonists. Backstrom $[1,2]$ has found that both ethanol and picrotoxin abolish the inhibitory surround of ganglion cell receptive fields and decrease the sensitivity of their rod mediated responses, while both agents increase the sensitivity of ganglion cell cone mediated responses. In addition, ethanol increases the latency of the responses, while picrotoxin has biphasic action - an initial decrease followed by an increase. Backstrom [1] suggested that ethanol has stronger effects on the conventional synapses made by horizontal and amacrine cells compared to the ribbon synapses made by bipolar cells. As a consequence, ethanol abolishes the lateral inhibition in the retina mediated by the GABAergic interneurons. Alcohol-induced decrease in lateral inhibition under different conditions of light adaptation has been also observed in humans with psychophysical performance in assessments of visual function $[\mathbf{3}, \mathbf{4}]$. Thus, it appears that some ethanol actions on visual functions are due to decreased lateral inhibition. This action could occur not only at the level of ganglion cells in the proximal retina, but also at the level of bipolar cells in the distal retina.

One of the easiest ways to characterize light responses of all groups of bipolar cells in vivo without perturbing any neuronal connections is by recording electroretinogram (ERG). The ERG consists of many components, but two of them are most prominent in response to long lasting stimuli: a b-wave (in response to stimulus onset) and a d-wave (in response to stimulus offset). The b-and d-waves are usually used for assessment of the retinal $\mathrm{ON}$ and OFF channel activity. There is general consensus that the neuronal generator of the b-wave is primarily the depolarizing $(\mathrm{ON})$ bipolar cells, while the d-wave generation depends mainly on the activity of hyperpolarizing (OFF) bipolar cells with minor contribution of the photoreceptor response at stimulus 
offset and activity of proximal retinal neurons [reviews: 5,6]. It has been demonstrated that ethanol has opposite effects on the ERG ON and OFF responses: it increases the amplitude of the b-wave, but it decreases the amplitude of the d-wave in amphibian and reptilian retina [7-13]. An increase of the b-wave amplitude has also been seen in dark adapted human ERG [14]. The ethanol effect on the b-wave amplitude is similar to that of picrotoxin (antagonist of $\mathrm{GABA}_{\mathrm{A}}$ and $\mathrm{GABA}_{\mathrm{C}}$ receptors), while its effect on the d-wave amplitude is opposite to that of picrotoxin (especially in frog retina) [for review: 15]. Thus, the blockade of the GABAergic transmission could account for the enhancing effect of ethanol on the ERG ON response, but it could not account for the depressing effect of ethanol on the ERG OFF response. This suggestion is in accordance with the results of Belcheva and Tzekov [12], who have demonstrated that picrotoxin eliminates the enhancing effect of ethanol on the b-wave amplitude, but it does not change (or even augments) the suppressive effect of ethanol on the $\mathrm{d}$-wave amplitude. The latter effect may be due to a suppressive action of ethanol directly on the OFF bipolar cells in distal retina or to its suppressive action on the third order retinal neurons, whose activity also contributes to the amphibian ERG OFF response. A distinction between these two possibilities could be made by comparing the effects of ethanol on the ERG d-wave in intact eyes with its effects in eyes, where the activity of proximal neurons has been blocked. It has been shown that N-methyl-D-aspartate (NMDA) applied in high concentrations (in milimolar range) depolarizes amacrine and ganglion cells and eliminates their light-evoked responses [16-20]. At the same time, NMDA has no effect on the light responses of photoreceptors and distal retinal neurons $[16,19,21-23]$. Thus, the NMDA treatment proved to be a useful tool for proximal retinal blockade.

In this study we compared the effects of ethanol on the ERG waves in intact frog eyecup preparations with its effects in eyecups, where the activity of proximal neurons has been blocked by $1 \mathrm{mM}$ NMDA. We found that ethanol enhances the amplitude of the b-wave and diminishes the amplitude of the $\mathrm{d}$-wave in the intact eyecups. The ethanol effects on both the b- and d-waves were fully preserved in eyecups treated with NMDA. The results presented indicate that ethanol effects on the amplitude and time course of the ERG b- and d-waves are due to its action in the distal frog retina.

\section{Methods}

The experiments were carried out on 54 dark adapted eyecup preparations of frog (Rana ridibunda), continuously superfused with Ringer solution $\left(\mathrm{NaCl} 110 \mathrm{mM}, \mathrm{KCl} 2.6 \mathrm{mM}, \mathrm{NaHCO}_{3} 10\right.$ $\mathrm{mM}, \mathrm{CaCl}_{2} 1.6 \mathrm{mM}, \mathrm{MgCl}_{2} 0.8 \mathrm{mM}$, Glucose $2 \mathrm{mM} ; \mathrm{HCl} 0.5$ $\mathrm{mM}$ to adjust $\mathrm{pH}$ to 7.8 ) at a rate of $1.8 \mathrm{ml} / \mathrm{min}$, temperature $16-18^{\circ} \mathrm{C}$ and supplied with moistened $\mathrm{O}_{2}$ [for details see 24]. The frogs were first anesthetized in water containing $500 \mathrm{mg} / \mathrm{l}$ Tricaine methanesulfonate (Sigma-Aldrich Chemie GmbH). They were then decapitated and pithed. The procedure has been approved by the local ethics committee and is in compliance with the ARVO Statement for the Use of Animals in Ophthalmic and Vision Research.

The effect of ethanol was assessed by perfusion of eyecups with solution of $1 \%$ ethanol dissolved in Ringer solution. The activity of proximal neurons was blocked using N-methyl-Daspartate (NMDA-Sigma-Aldrich), dissolved in Ringer solution to a concentration of $1 \mathrm{mM}$. The same concentration has been used in our previous studies $[\mathbf{2 4 , 2 5}]$ and by other authors working on amphibian retina [26-28]. The saturating nature of this NMDA concentration was tested in our previous work [25].

\section{Experimental procedure}

The frogs were dark adapted for $24 \mathrm{~h}$ and then the eyecup preparation was made under dim red light. The rhythmic light stimulation began after additional period of dark adaptation for 30 minutes. Diffuse white light stimuli ( $150 \mathrm{~W}$ tungsten halogen lamp) with $5 \mathrm{~s}$ duration were presented repeatedly at interstimulus interval of $25 \mathrm{~s}$ during period of 40 minutes. The light intensity was $5.4 \times 10^{3}$ quanta $\mathrm{s}^{-1} \mu \mathrm{m}^{-2}(0.45 \mathrm{~lx})$ falling at the plane of the retina. Results are based on 54 experiments, divided into 4 experimental groups according to the substances applied: 1) Control group $(\mathrm{n}=12)$. Eyecups were perfused with Ringer solution throughout the whole 40 minutes period. 2) Ethanol group $(\mathrm{n}=15)$. In preliminary experiments $(\mathrm{n}=4)$ three different concentrations of ethanol $(0.25 \%, 0.5 \%$ and $1 \%)$ was tested in order to obtain dose-response relationship. In the main group of experiments $(n=11)$ the eyecups were perfused with Ringer solution for 10 minutes firstly and afterwards with $1 \%$ ethanol for 30 minutes. 3) NMDA group $(\mathrm{n}=14)$. The eyecups were perfused with Ringer solution for 10 minutes firstly and afterwards with $1 \mathrm{mM}$ NMDA for 30 minutes. 4) NMDA+Ethanol group $(\mathrm{n}=13)$. The eyecups were perfused with Ringer solution for 10 minutes firstly, followed by 3 minute period of perfusion with $1 \mathrm{mM}$ NMDA and afterwards the perfusion was switched to Ringer solution containing $1 \mathrm{mM}$ NMDA+1\% ethanol. In two of the experiments in this group the order of treatment was revised-the eyecups were perfused with $1 \%$ ethanol firstly and with $1 \%$ ethanol +1 mM NMDA afterwards.

\section{ERG recording and data analysis}

The electroretinograms were recorded by means of non-polarized $\mathrm{Ag} / \mathrm{AgCl}$ electrodes at bandpass of $0.1-1000 \mathrm{~Hz}$ (DC/AC differential amplifier model 3000; A-M Systems) and digitized at $2000 \mathrm{~Hz}, 16$ bit resolution (Data acquisition system Biopac MP 150). The amplitude of the $b$-wave was measured from the peak of the a-wave to the peak of the b-wave, while that of the d-wave was measured from the baseline to the peak of the wave. The latency of the ERG waves was measured from stimulus onset (for b-wave) or offset (for d-wave) to the beginning of the wave, while their implicit time was measured from stimulus onset (for b-wave) or offset (for d-wave) to the peak of the wave.

Student's t-test and Two-Way ANOVA (OriginPro 8 software, OriginLab Corporation, Northhampton, MA) were used for statistical evaluation of the data. 


\section{Results}

\section{Control group}

The amplitude of both the b-and d-waves remained unchanged during the entire course of the experiment when the retina was perfused with Ringer solution only (Figures $\mathbf{1} \mathbf{a}$ and $\mathbf{1 b}$ ). The same was true for the time course of the responses. Both the latency and implicit time of the ERG waves were not significantly altered during the perfusion with Ringer solution (Table 1).

\section{Ethanol group}

In preliminary experiments three different concentrations of ethanol-0.25\% ( 54 mM), 0.5\% ( 109 $\mathrm{mM})$ and $1 \%(\sim 217 \mathrm{mM})$ were tested in order to obtain dose-response relationship. All three concentrations caused significant increase of the b-wave amplitude and decrease of the d-wave amplitude in comparison with the corresponding values obtained in the control group
(Figure 1c). The effect was most pronounced (especially for the d-wave amplitude) with the highest concentration of ethanol. That's why the concentration of $1 \%$ ethanol was chosen for the main group of experiments. Similar concentrations of ethanol have been used by other authors working on isolated preparations in vitro [29-31].

The amplitude of the ERG waves in the main group of experiments was very stable in the initial control period. Switching the perfusion to $1 \%$ ethanol solution caused marked increase of the $b$-wave amplitude and diminution of the $\mathrm{d}$-wave amplitude. The effect developed rapidly and reached a plateau sooner for the $\mathrm{b}$-wave $\left(8^{\text {th }} \mathrm{min}\right)$ than for the $\mathrm{d}$-wave $\left(15^{\text {th }} \mathrm{min}\right)$ (Figures $1 \mathrm{a}$ and $\mathbf{1 b}$ ). During the plateau period the amplitude of the $b$ - and $\mathrm{d}$-wave differed significantly from the corresponding values obtained in the control group (Two-way ANOVA, $\mathrm{p}<0.0001$ ). Perfusion with ethanol did not alter significantly the latency

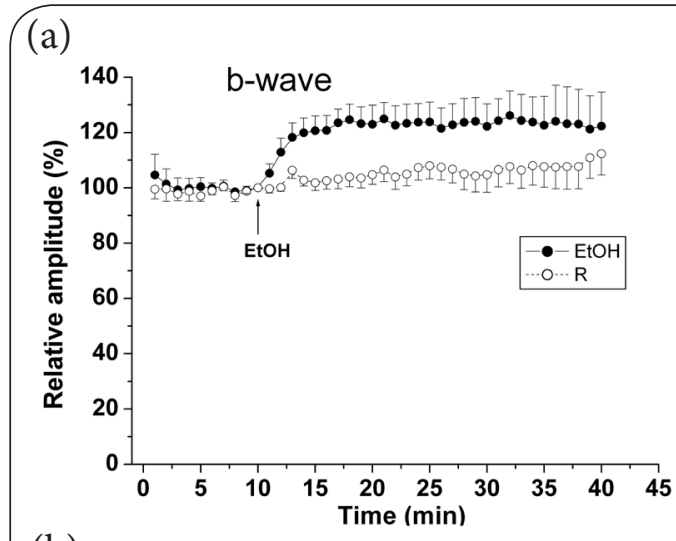

(b)

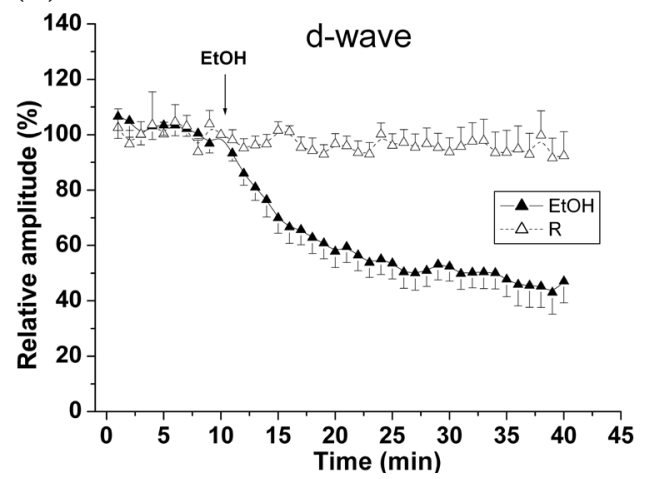

(c)

(d)
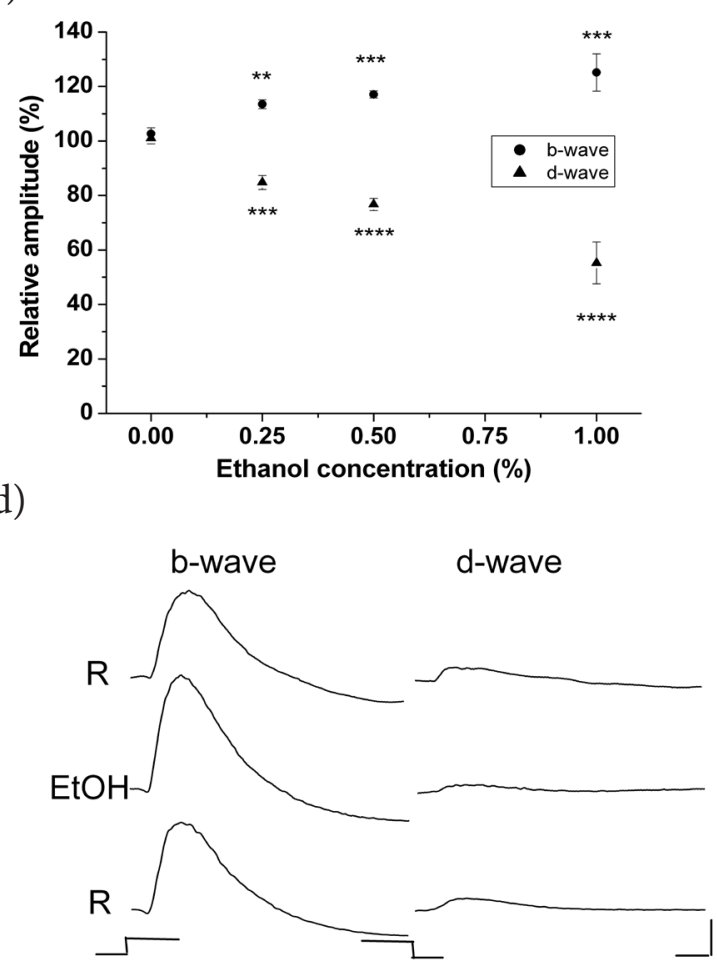

Figure 1. (a,b) Time course of the effects of $1 \%$ ethanol on the amplitude of the ERG b-and d-wave. Results of both control experiments (open symbols) and test experiments of main group (filed symbols) are represented. The amplitude of the ERG waves is normalized to the values obtained just prior ethanol application. The time, when the perfusion was switched to $1 \%$ ethanol solution $(\mathrm{EtOH})$, is indicated by an arrow. Mean values \pm SEM are shown. (c) Dose-response relationship for ethanol effects on the b- and d-wave amplitude. The amplitude of the ERG waves during treatment with 3 different concentrations of ethanol $(0.25 \%, 0.5 \%$ and $1 \%)$ are compared to the corresponding values obtained in the control experiments $(0 \%$ ethanol). The statistical significance of the obtained differences is denoted as: ${ }^{* *} \mathrm{p}<0.01 ;{ }^{* * *} \mathrm{p}<0.005 ;{ }^{* * * *} \mathrm{p}<0.0001$. (d) Original ERG records (b-and $\mathrm{d}$-wave), obtained during the perfusion with Ringer solution in the control period (upper row), $1 \%$ ethanol (middle row) and Ringer solution in the recovery period (bottom row) . Calibration: time $-0.2 \mathrm{~s}$; amplitude $-50 \mu \mathrm{V}$. 
Popova et al, Journal of Psychiatry and Brain Functions 2015,

Table 1. Effects of ethanol, NMDA and combined NMDA+ethanol application on the time characteristics of the ERG b- and d-wave (means \pm SEM).

\begin{tabular}{lllll}
\hline $\begin{array}{l}\text { Time from the beginning of } \\
\text { experiment }\end{array}$ & $\begin{array}{c}\text { Latency } \\
\text { b-wave }(\mathbf{m s})\end{array}$ & $\begin{array}{l}\text { Implicit time } \\
\text { b-wave }(\mathbf{m s})\end{array}$ & $\begin{array}{l}\text { Latency } \\
\text { d-wave }(\mathbf{m s})\end{array}$ & $\begin{array}{l}\text { Implicit time } \\
\text { d-wave }(\mathbf{m s})\end{array}$ \\
\hline $\begin{array}{l}\text { Ringer group } \\
10 \text { min }\end{array}$ & $118 \pm 5.2$ & $327 \pm 17.9$ & $110 \pm 4.9$ & $313 \pm 15.2$ \\
27 min & $123 \pm 3.8$ & $330 \pm 13.4$ & $113 \pm 6.5$ & $307 \pm 14.2$ \\
\hline $\begin{array}{l}\text { Ethanol group } \\
10 \text { min }\end{array}$ & $122 \pm 4.4$ & $327 \pm 11.9$ & $110 \pm 3.7$ & $322 \pm 16.8$ \\
27 min & $116 \pm 6.1$ & $319 \pm 14.0$ & $127 \pm 6.5$ & $377 \pm 25.3$ \\
& & & $\mathrm{p}<0.0005$ & $\mathrm{p}<0.003$ \\
\hline NMDA group & $115 \pm 4.9$ & $317 \pm 9.2$ & $112 \pm 5.2$ & $315 \pm 14.4$ \\
10 min & $131 \pm 5.4$ & $348 \pm 8.3$ & $117 \pm 5.9$ & $306 \pm 16.3$ \\
13 min & $\mathrm{p}<0.034$ & $\mathrm{p}<0.0005$ & & \\
& $142 \pm 5.2$ & $344 \pm 8.6$ & $153 \pm 7.0$ & $314 \pm 25.2$ \\
27 min & $\mathrm{p}<0.0001$ & $\mathrm{p}<0.0001$ & $\mathrm{p}<0.0001$ & \\
& & & & \\
& $120 \pm 5.8$ & $319 \pm 14.2$ & $119 \pm 5.9$ & $310 \pm 13.8$ \\
NMDA+ thanol group & $131 \pm 3.8$ & $374 \pm 8.5$ & $109 \pm 6.0$ & $299 \pm 15.0$ \\
10 min & $\mathrm{p}<0.007$ & $\mathrm{p}<0.003$ & & \\
13 min & $125 \pm 3.7$ & $353 \pm 9.9$ & & \\
& & $* \mathrm{p}<0.018$ & & \\
27 min & &
\end{tabular}

Statistics: $13^{\text {th }}$ or $27^{\text {th }}$ minute compared to $10^{\text {th }}$ minute ${ }^{*}-13^{\text {th }}$ and $27^{\text {th }}$ minutes compared

and implicit time of the b-wave, although a tendency for their shortening emerged (Table 1). On the other hand, ethanol caused significant lengthening of the d-wave time parameters (Table 1). Both the latency and implicit time of the OFF response were significantly delayed. The amplitude of the ERG waves recovered considerably, when the perfusion was switched again to Ringer solution (Figure 1d).

\section{NMDA group}

Perfusion with $1 \mathrm{mM}$ NMDA influenced the $b$ - and d-wave amplitude in a way similar to that of ethanol. Although the b-wave amplitude showed small initial diminution (lasting $\sim 3 \mathrm{~min}$ ), it recovered soon and increased considerably afterwards (Figure 2a). The NMDA enhancing effect on the b-wave amplitude was very stable in time. During the plateau period $\left(20^{\text {th }}-30^{\text {th }} \mathrm{min}\right)$ its amplitude was significantly higher (Two-way ANOVA, $\mathrm{p}<0.0001$ ) compared to the corresponding values obtained in the control group. Perfusion with NMDA altered the time characteristics of the b-wave (Figure 2c). Both the latency and the implicit time of the response were significantly lengthened (Table 1). In this respect NMDA effect on the ERG ON response differed from that obtained during the ethanol treatment. Proximal retinal blockade with NMDA caused great diminution of the d-wave amplitude. The effect developed very rapidly-within the first 3 minutes of the blockade it was almost fully expressed (Figure $\mathbf{2 b}$ ). The effect was very stable during the subsequent 10-12 minutes and a tendency for a greater diminution emerged afterwards. During this time period $\left(13^{\text {th }}-30^{\text {th }}\right.$ minute $)$ the amplitude values of the d-wave were significantly lower (Two-way ANOVA, $\mathrm{p}<$ 0.0001 ) than the corresponding values obtained in the control group. The d-wave time course was not altered during the early period of the NMDA perfusion (Table 1 see $13^{\text {th }}$ minute). A significant lengthening of the latency, but not of the implicit time of the OFF response was later observed (Table 1 see $27^{\text {th }}$ minute). The effects of NMDA on the ERG waves were reversible to a great extent during the subsequent perfusion with Ringer solution (Figure 2c).

\section{Ethanol+NMDA group}

After the initial control period, the eyecups in this group were treated with NMDA alone for 3 minutes and with combination of NMDA and ethanol afterwards. As it could be expected from the results of the previous group, perfusion with NMDA caused great diminution of the d-wave amplitude without altering its time characteristics (Figures 3b-3d) (Table $\mathbf{1}$ ). The b-wave amplitude was not changed during this short ( 3 minute) period, and the latency and the implicit time of the response were already significantly delayed (Figures $\mathbf{3 b} \mathbf{b}-\mathbf{3 d}$ ) (Table $\mathbf{1}$ ), as expected. Subsequent perfusion with NMDA+ethanol caused addition diminution of the d-wave amplitude and great enhancement of the b-wave amplitude (Figures $\mathbf{3} \mathbf{a}$ and $\mathbf{3 b} \mathbf{b}$ ). The enhancement of the b-wave amplitude was accompanied with significant shortening of its implicit time (Figures $\mathbf{3 c}$ and $\mathbf{3 d}$ ) (Table 1). Thus, the tendency for speeding up of the b-wave time course seen in ethanol group was strongly expressed on the background of proximal retinal blockade. The increase of the $b$-wave amplitude during combined NMDA+ethanol treatment was significantly greater than its increase during the perfusion with ethanol or NMDA alone (Two-way ANOVA, $\mathrm{p}<0.0001$ ) (Figure 4a). This indicated that the enhancing effect of ethanol on the b-wave 

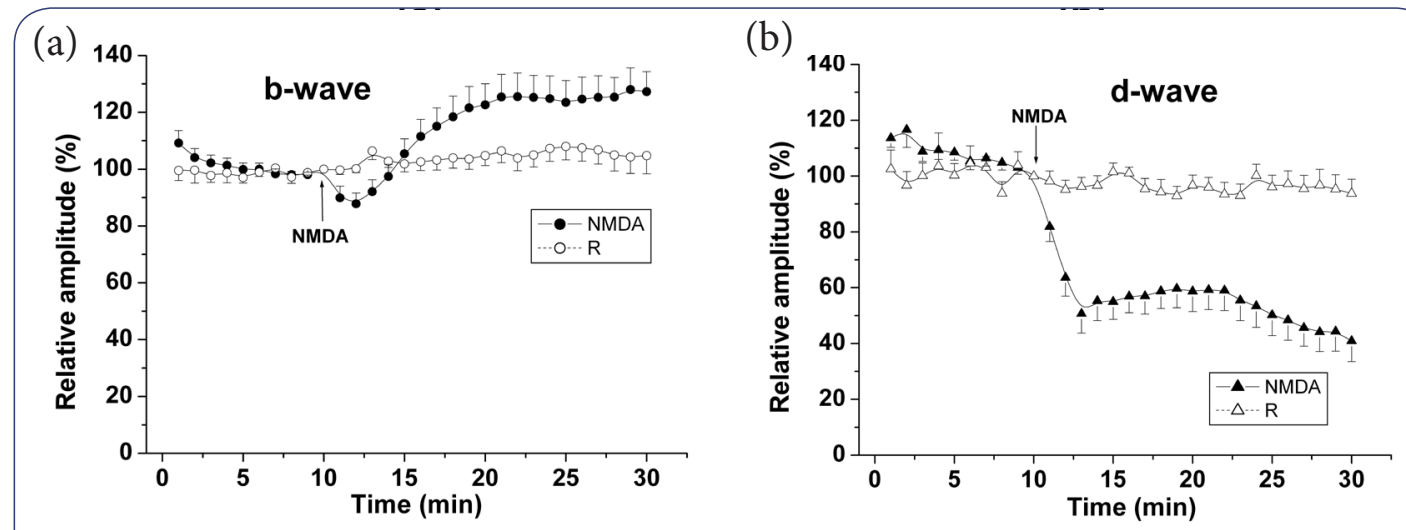

(c)

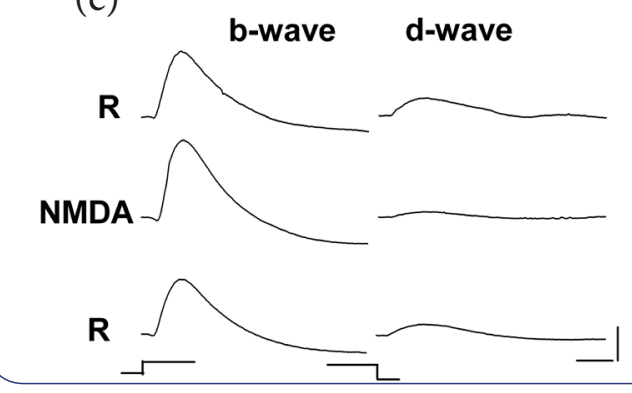

Figure 2. (a,b) Time course of the NMDA effects on the amplitude of the ERG b- and d-wave. Results of both control experiments (open symbols) and test experiments (filed symbols) are represented. All designations are the same as Figures $\mathbf{1 a}$ and $\mathbf{1 b}$. (c) Original ERG records (b- and d-wave), obtained during the perfusion with Ringer solution in the control period (upper row), NMDA (middle row) and Ringer solution in the recovery period (bottom row). Calibration: time $-0.2 \mathrm{~s}$; amplitude $-50 \mu \mathrm{V}$.
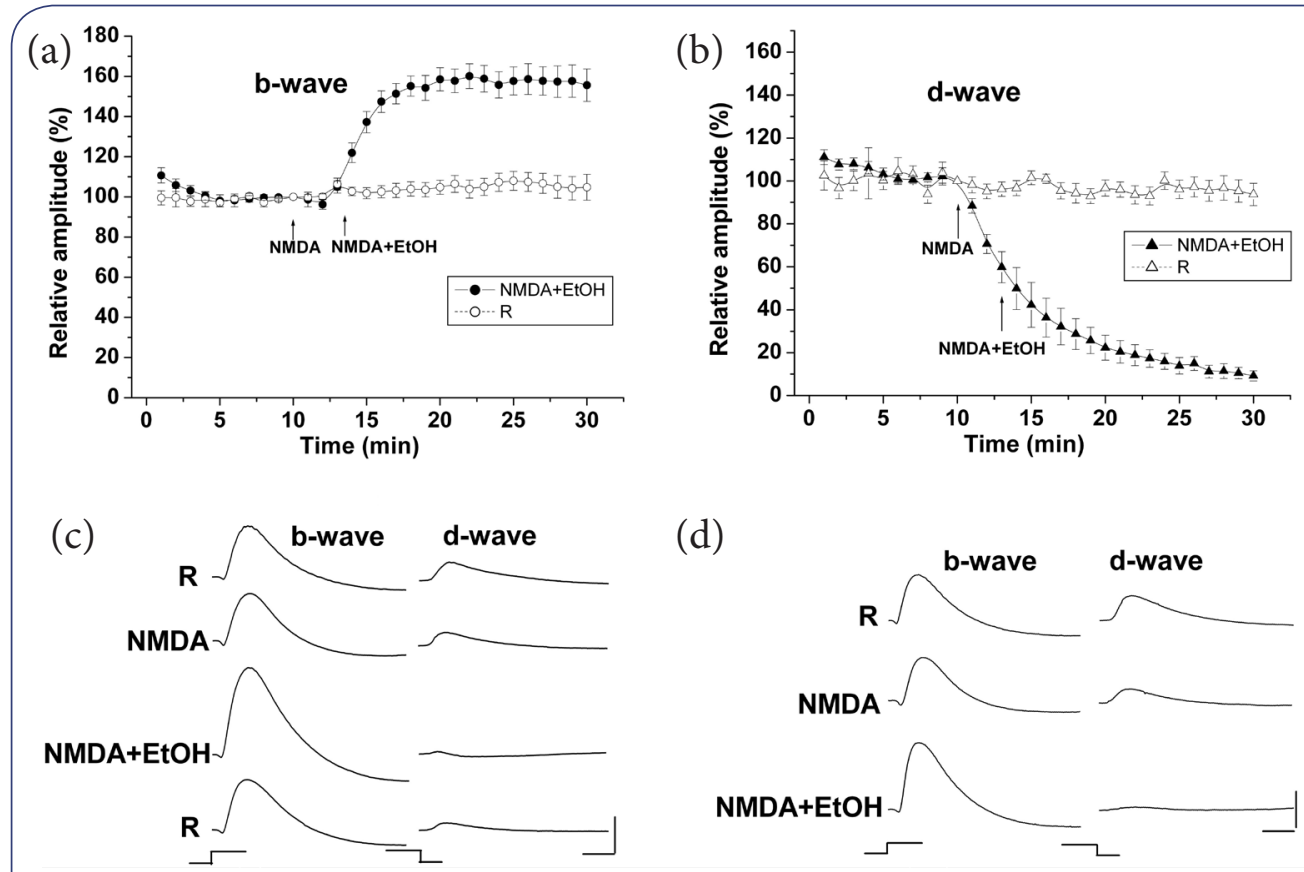

(d)

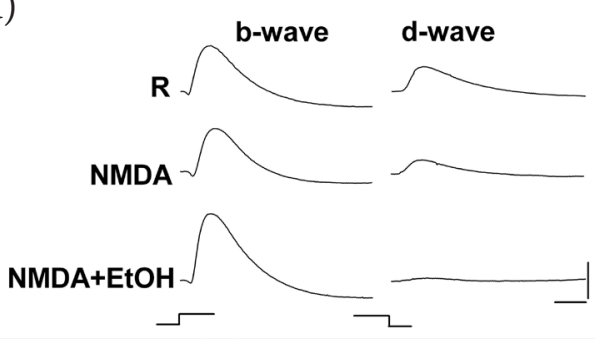

Figure 3. (a,b) Combined effects of NMDA and ethanol on the amplitude of the ERG b-and d-wave. Results of both control experiments (open symbols) and test experiments (filed symbols) are represented. The times, when the perfusion was switched to NMDA and NMDA+ethanol solution, are indicated by arrows. All designations are the same as Figures 1a and 1b. (c) Original ERG records (b- and d-wave), obtained during the perfusion with Ringer solution in the control period (upper row), NMDA, NMDA+Ethanol and Ringer solution in the recovery period (bottom row). It can be seen that the positive d-wave disappeared during combined NMDA+ethanol perfusion and reappeared again in the recovery period. Calibration: time $-0.2 \mathrm{~s}$; amplitude $-50 \mu \mathrm{V}$. (d) Original ERG records obtained from an experiment where a small positive d-wave was preserved during the combined NMDA+ethanol perfusion. Calibration: time $-0.2 \mathrm{~s}$; amplitude $-0 \mu \mathrm{V}$. 
amplitude was fully developed during NMDA treatment and that it did not depend on the activity of proximal retinal neurons. The same was true for the depressing effect of ethanol on the amplitude of the d-wave. The diminution of the d-wave amplitude during combined ethanol + NMDA treatment was significantly greater than that obtained during isolated ethanol or NMDA application (Two-way ANOVA, p<0.0001) (Figure 4b). The pure effect of ethanol on the d-wave amplitude in these eyecups (pretreated with NMDA) was practically the same as that obtained in the ethanol group (Figure 4c). This indicates that the effect of ethanol on the d-wave amplitude did not depend on the activity of proximal retinal neurons. The d-wave disappeared during combined NMDA+ethanol treatment in some experiments and it was substituted with negative response (Figure 3c). This fact did not allow us to measure the time characteristics of the d-wave in all experiments. In experiments where the d-wave was preserved, its latency and implicit time were considerably delayed (Figure 3d), indicating that the ethanol effect on the implicit time of the $\mathrm{d}$-wave was also evident during blockade of proximal retinal neurons. The b-and d-waves recovered to some extent when the eyecups were perfused again with Ringer solution (Figure 3c).

In two experiments of this group the order of treatments was reversed-the eyecups were perfused with ethanol for 10 minutes firstly and with ethanol+NMDA afterwards. Ethanol caused an increase of the b-wave amplitude and a decrease of the d-wave amplitude (Figure 4d). The combined perfusion with ethanol and NMDA caused an additional enhancement of the b-wave amplitude and additional diminution of the d-wave amplitude, which lead to full suppression of the positive OFF response (Figure 4d). This indicated that the effects of ethanol and NMDA on the ERG waves were independent and that ethanol did not prevent the NMDA action on those ERG waves.

\section{Discussion}

The results obtained in this study clearly show that ethanol enhances the b-wave amplitude and diminishes the d-wave amplitude in all concentrations tested. It significantly slows the time course of the OFF response and tends to speed up the time course of the $\mathrm{ON}$ response. This indicates that ethanol has overall
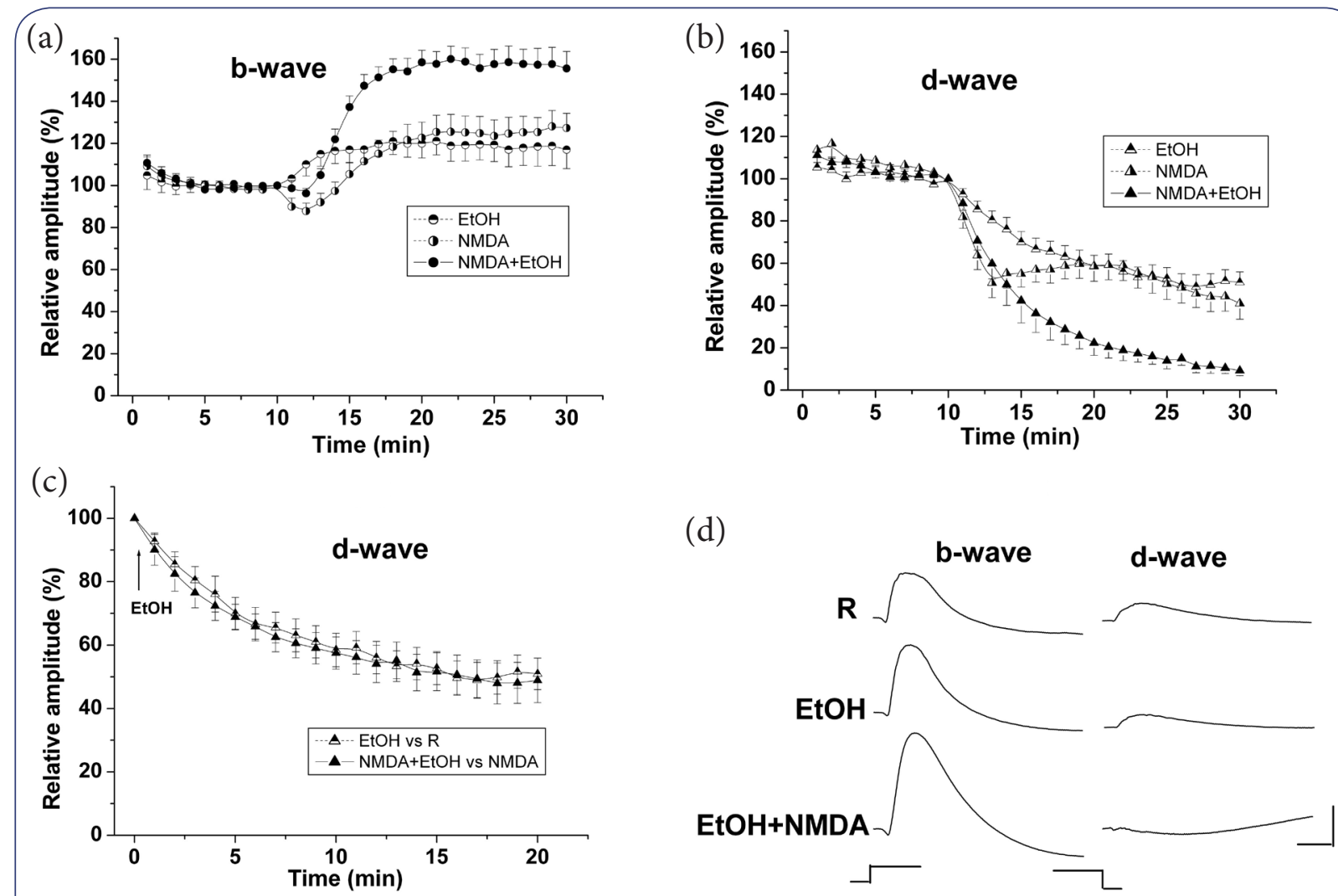

Figure 4. (a,b) Comparison of the effects of ethanol alone, NMDA alone and combined NMDA+ethanol perfusion on the amplitude of the ERG waves. The symbols used for the different groups are shown in the legend. (c) Comparison of the pure effects of ethanol obtained without pretreatment of the eyecups with NMDA (EtOH vs R) and with their pretreatment with NMDA (EtOH+NMDA vs NMDA). Each point on the curves is obtained by subtracting the d-wave amplitude at that moment from the value measured just before the ethanol application $\left(10^{\text {th }}\right.$ minute for ethanol group and 13 th minute for $\mathrm{NMDA}+\mathrm{EtOH}$ group). All amplitudes are normalized as in $(\mathbf{a}, \mathbf{b})$. The moment of ethanol application (zero point on the abscissa) is denoted by an arrow. (d) Original ERG records (b- and d-wave), obtained in an experiment where the eyecup was perfused first with ethanol and with combined NMDA+ethanol afterwards. Calibration: time $-0.2 \mathrm{~s} ;$ amplitude $-50 \mu \mathrm{V}$. 
stimulating action on the mechanisms responsible for b-wave generation and overall depressing action on the mechanisms responsible for $\mathrm{d}$-wave generation. These opposite effects of ethanol on the ERG ON and OFF responses are seen in general anesthetic concentrations. The described effects of ethanol on the ERG waves were fully preserved in eyecups treated with high doses of NMDA in order to block the activity of proximal retinal neurons. Perfusion with NMDA alone caused an increase of the b-wave amplitude and a diminution of the d-wave amplitude, indicating that the activity of proximal neurons directly contributes to generation of the d-, but not b-wave in frog ERG. The present findings are in line with previously reported NMDA effects on amphibian b- and d-waves $[\mathbf{2 4}, \mathbf{2 5}, \mathbf{2 8}, \mathbf{3 2}]$ and mammalian b-wave [33-35]. The enhancement of the b-wave amplitude caused by NMDA has been attributed to disruption of inhibitory pathways from proximal neurons to ON bipolars cells, because b-wave enhancement is reversed after blockade of GABAergic and glycinergic retinal synapses [28].

The preserved effects of ethanol on the ERG waves during NMDA treatment indicate that these effects are independent from the activity of proximal retinal neurons. Thus, it appears that an action of ethanol in the distal retina is responsible for its stimulating effect on the b-wave and its depressing effect on the $\mathrm{d}$-wave. The effect on the b-wave may be due to ethanol blockade of inhibitory influences exerted upon the ON bipolar cells in the outer plexiform layer. It has been shown that the enhancing effect of ethanol on the $b$-wave amplitude is prevented by picrotoxin $\left(\mathrm{GABA}_{\mathrm{A}}\right.$ and $\mathrm{GABA}_{\mathrm{C}}$ receptor antagonist), but not strychnine (glycine receptor antagonist) $[11,12]$. There findings indicate that the GABAergic, but not glycinergic neurotransmitter system is involved in ethanol action on the ERG ON response. It is known that GABAergic horizontal cells mediate inhibitory influences upon bipolar cells in the outer plexiform layer [for review: 15]. The significance of this distal action of GABA for the b-wave generation in frog retina has been demonstrated in our recent study [25]. It has been shown that the blockade of proximal retinal activity with NMDA did not prevent the enhancing effect of picrotoxin on the $b$-wave amplitude. These results suggest that the endogenous GABA released by horizontal cells in the distal retina has an inhibitory effect on the activity of ON bipolar cells, whose activity is responsible for the b-wave generation. If ethanol depresses the activity of these GABAergic horizontal cells, the ON bipolar cells would be disinhibited and their light responses and respectively b-wave would be augmented. The mechanism of the suppressing effect of ethanol on horizontal cell activity is largely unknown. It may be due to inhibition of their non-NMDA ionotropic glutamate receptors (AMPA/ kainate) that respond to glutamate released by the photoreceptors [reviews: 36,37]. Many data indicate that ethanol reduces AMPA and kainate currents (including synaptic responses) in non-retinal neurons [review: 38]. If ethanol has similar actions on horizontal cells, it could decrease their light-modulated responses and thus diminish their inhibitory influences upon the ON bipolar cells. The latter effect could account for the en- hancement of the b-wave amplitude during ethanol treatment.

The depressing effect of ethanol on the d-wave also appears to take place in the distal retina. We have demonstrated that the inhibitory action of ethanol on the ERG OFF response was fully preserved during proximal retinal blockade. It has been shown that this ethanol action was fully preserved also during perfusion with picrotoxin [12] and strychnine [11], indicating that it depends neither on the GABAergic nor on the glycinergic neurotransmission in frog retina. In our previous work we have demonstrated that the relative decrease of the d-wave amplitude after ethanol treatment is invariant to the intensity of stimulation and to the initial amplitude of the d-wave [13]. All these facts support the suggestion that the ethanol effect on the ERG $\mathrm{d}$-wave is due to its direct inhibitory action on the OFF bipolar cells. The mechanism of this inhibitory action may be the same as that on the horizontal cells - inhibition of their non-NMDA ionotropic glutamate receptors (AMPA/kainate) that respond to glutamate released by the photoreceptors [reviews: 36,37]. Thus, it appears that one and the same mechanism - inhibition of non-NMDA ionotropic glutamate receptors on horizontal and OFF bipolar cells, may be responsible for the enhancing effect of ethanol on the ERG ON response and its depressing effect on the ERG OFF response. The activity of metabotropic glutamate receptors (mGluR6) that mediate the responses of the ON bipolar cells to glutamate released by the photoreceptors [for review: 39 ] is probably not inhibited by ethanol, because their inhibition would cause diminution, but not enhancement of the b-wave amplitude. The disturbed balance between the retinal $\mathrm{ON}$ and OFF channel activity (at bipolar cell level) could contribute to the well known suppressive effect of ethanol on the rapid temporal processing in human visual system [for review: 40]. It is well established that OFF bipolar cells and OFF ganglion cells response to higher frequency stimuli than their respective ON counterparts $[\mathbf{4 1 , 4 2}]$. If ethanol selectively diminishes the OFF channel activity, it could lead to slower temporal processing of visual information in the retina.

The results of the present study indicate also that ethanol does not prevent NMDA effects on the ERG waves. This means that ethanol does not inhibit NMDA receptor mediated currents in proximal retinal neurons. However, some electrophysiological as well as biochemical studies have clearly demonstrated that ethanol inhibits NMDA receptor currents and NMDA receptor mediated responses in non-retinal neurons [reviews: $\mathbf{3 8 , 4 3 , 4 4}$ ]. Thus, the NMDA receptor is considered one of the primary molecular targets of ethanol in the brain. The preserved NMDA effect on the ERG waves during ethanol treatment in the present study is probably due to high concentration of NMDA (1 mM) used in our experiments. Much lower NMDA concentrations (in micromolar range) have been used in all experiments, where the effects of ethanol on NMDA receptor-mediated responses elicited by exogenously applied NMDA, have been investigated [45-50]. It is largely unknown what would be the ethanol effect on the NMDA currents of proximal retinal neurons when they are elicited by physiological concentrations of NMDA. Further 
studies are needed to evaluate this subject.

It is known that ethanol alters membrane of the neurons as well as their ion channels, enzymes, and receptors for some neurotransmitters (acetylcholine, serotonin, dopamine). However, a non-specific alternation of neuronal (bipolar cell) membrane properties could hardly account for the opposite effects of ethanol on the ERG b- and d-waves observed in the present study. The involvement of other neurotransmitters (acetylcholine, serotonin, dopamine) in the ethanol effects on the ERG waves could not be rule out, but unfortunately there are no available data concerning the interactions of ethanol with these neurotransmitters in modulating the ERG responses. Thus, discussing their participation in the observed ethanol effects on the frog ERG b- and d-waves would be quite speculative.

\section{Conclusion}

Our results clearly show that proximal retinal blockade does not alter the enhancing effect of ethanol on the ERG b-wave and its depressing effect on the ERG d-wave. These results indicate that an action of ethanol in the distal retina is responsible for its effects on the frog ERG waves. Further studies are needed to elucidate the exact mechanisms underlying ethanol effects in the distal retina.

\section{Competing interests}

The authors declare that they have no competing interests.

\section{Authors' contributions}

The manuscript was written by E. Popova. The study was designed by E. Popova and P. Kupenova, who also did the statistics. A. Kuzeva, S. Panev and D. Zhekova were involved in experimental work and analyzing the resulting data.

\section{Publication history}

Editors:Vinay Parikh, Temple University, USA.

Eric Andrew Engleman, Indiana University School of Medicine, USA. Received: 01 June 2015 Revised: 09 July 2015

Accepted: 27 July 2015 Published: 28 July 2015

\section{References}

1. Backstrom AC. Effects of alcohol on ganglion cell receptive field properties and sensitivity in the frog retina. Adv Exp Med Biol. 1977; 85B:187-208. | PubMed

2. Backstrom AC. Effects of picrotoxin on sensitivity and receptive field properties of ganglion cells in the frog retina. Med Biol. 1981; 59:234-46. I PubMed

3. Johnston KD and Timney B. Effects of acute ethyl alcohol consumption on a psychophysical measure of lateral inhibition in human vision. Vision Res. 2008; 48:1539-44. | Article | PubMed

4. Johnston $\mathrm{K}$ and Timney $\mathrm{B}$. Alcohol and lateral inhibitory interactions in human vision. Perception. 2013; 42:1301-10. | Article | PubMed

5. Perlman I. The Electroretinogram: ERG. In: Kolb H, Fernandez E, Nelson R, (eds). Webvision: The Organization of the Retina and Visual System [Internet]. Salt Lake City (UT): University of Utah Health Sciences Center. 1995.

6. Frishman L.J. Origins of the electroretinogram. In: Heckenlively JR, Arden GB (eds). Principles and Practice of Clinical Electrophysiology of Vision. 2nd ed. London: MIT Press. 2006; 139-183.

7. Forbes $A$, Burleigh $S$ and Neyland $M$. Electric responses to color shift in frog and turtle retina. J Neurophysiol. 1955; 18:517-35. | Article | PubMed

8. Bernhard CG, Knave B and Persson HE. Differential effects of ethyl alcohol on retinal functions. Acta Physiol Scand. 1973; 88:373-81. | Article | PubMed

9. Dick E and Miller RF. Light-evoked potassium activity in mudpuppy retina: its relationship to the b-wave of the electroretinogram. Brain Res. 1978; 154:388-94. | Article | PubMed

10. Dick E, Miller R.F, Daucheux R.F. Neuronal origin of the $\mathbf{b}$ - and d-waves in the I-type ERG. Invest Ophthalmol Vis Sci. 1979; 18:34.

11. Belcheva S, Mitova L. Combine effects of strychnine and ethanol on the frog ERG. C R Acad Bulg Sci. 1983; 36: 1085-1088.

12. Belcheva $S$, and Tzekov R. Combine effects of picrotoxin and ethanol on the frog ERG. Electroencephalogr Clin Neurophysiol. 1983; 55:23P-27.

13. Belcheva S, Popova E. Effects of ethanol on the frog electroretinogram at different stimulus intensities. CR Acad Bulg Sci. 1985; 38:145-148.

14. Ikeda H. Effects of ethyl alcohol on the evoked potential of the human. Eye Vision Res. 1963; 3:155-169. | Article

15. Popova E. lonotropic GABA Receptors and Distal Retinal ON and OFF Responses. Scientifica (Cairo). 2014; 2014:149187. | Article | PubMed Abstract I PubMed FullText

16. Slaughter MM and Miller RF. The role of excitatory amino acid transmitters in the mudpuppy retina: an analysis with kainic acid and N-methyl aspartate. J Neurosci. 1983; 3:1701-11. | Article | PubMed

17. Lukasiewicz PD and McReynolds JS. Synaptic transmission at N-methylD-aspartate receptors in the proximal retina of the mudpuppy. J Physiol. 1985; 367:99-115. | PubMed Abstract | PubMed FullText

18. Coleman PA and Miller RF. Do N-methyl-D-aspartate receptors mediate synaptic responses in the mudpuppy retina? J Neurosci. 1988; 8:472833. | Article | PubMed

19. Stockton RA and Slaughter MM. B-wave of the electroretinogram. A reflection of ON bipolar cell activity. J Gen Physiol. 1989; 93:101-22. | Article | PubMed Abstract | PubMed FullText

20. Dixon DB and Copenhagen DR. Two types of glutamate receptors differentially excite amacrine cells in the tiger salamander retina. $J$ Physiol. 1992; 449:589-606. | PubMed Abstract | PubMed FullText

21. Massey SC and Miller RF. Excitatory amino acid receptors of rod- and cone-driven horizontal cells in the rabbit retina. J Neurophysiol. 1987; 57:645-59. | Article | PubMed

22. Yang $X L$ and $W u S M$. Coexistence and function of glutamate receptor subtypes in the horizontal cells of the tiger salamander retina. Vis Neurosci. 1991; 7:377-82. | PubMed

23. Krizaj D, Akopian A and Witkovsky P. The effects of L-glutamate, AMPA, quisqualate, and kainate on retinal horizontal cells depend on adaptational state: implications for rod-cone interactions. J Neurosci. 1994; 14:5661-71. | Article | PubMed

24. Popova $E$ and Kupenova P. Contribution of proximal retinal neurons to b- and d-waves of frog electroretinogram under different conditions of light adaptation. Vision Res. 2009; 49:2001-10. | Article | PubMed

25. Popova E. Effects of picrotoxin on light adapted frog electroretinogram are not due entirely to its action in proximal retina. Vision Res. 2014; 101:138-50. | Article | PubMed

26. Arnarsson A and Eysteinsson T. Modification of the Xenopus electroretinogram by actions of glycine in the proximal retina. Acta Physiol Scand. 2000; 169:249-58. | Article | PubMed

27. Arnarsson $A$ and Eysteinsson $T$. The role of GABA in modulating the Xenopus electroretinogram. Vis Neurosci. 1997; 14:1143-52. | PubMed

28. Awatramani G, Wang J and Slaughter MM. Amacrine and ganglion cell contributions to the electroretinogram in amphibian retina. Vis Neurosci. 2001; 18:147-56. | Article | PubMed

29. Nie Z, Madamba SG and Siggins GR. Ethanol inhibits glutamatergic 
neurotransmission in nucleus accumbens neurons by multiple mechanisms. J Pharmacol Exp Ther. 1994; 271:1566-73. | Article | PubMed

30. Martin D, Tayyeb MI and Swartzwelder HS. Ethanol inhibition of AMPA and kainate receptor-mediated depolarizations of hippocampal area CA1. Alcohol Clin Exp Res. 1995; 19:1312-6. | Article I PubMed

31. Wang MY, Rampil IJ and Kendig JJ. Ethanol directly depresses AMPA and NMDA glutamate currents in spinal cord motor neurons independent of actions on GABAA or glycine receptors. J Pharmacol Exp Ther. 1999; 290:362-7. | Article | PubMed

32. Katz B.J, Wen R, Zheng J.B, Xu Z.A and Oakley B. $2^{\text {nd }} \mathbf{M}$-wave of the toad electroretinogram. J Neurophysiol, 1991; 66:1927-1940.

33. Gargini C, Demontis GC, Cervetto L and Bisti S. Analysis of pharmacologically isolated components of the ERG. Vision Res. 1999; 39:1759-66. | Article | PubMed

34. Ohzeki T, Machida S, Takahashi T, Ohtaka K and Kurosaka D. The Effect of intravitreal N-methyl-DL-aspartic acid on the electroretinogram in Royal College of surgeons rats. Jpn J Ophthalmol. 2007; 51:165-74. | Article | PubMed

35. Hare WA and Wheeler L. Experimental glutamatergic excitotoxicity in rabbit retinal ganglion cells: block by memantine. Invest Ophthalmol Vis Sci. 2009; 50:2940-8. | Article | PubMed

36. Thoreson WB and Witkovsky P. Glutamate receptors and circuits in the vertebrate retina. Prog Retin Eye Res. 1999; 18:765-810. | Article | PubMed

37. Yang XL. Characterization of receptors for glutamate and GABA in retinal neurons. Prog Neurobiol. 2004; 73:127-50. I Article I PubMed

38. Dopico AM and Lovinger DM. Acute alcohol action and desensitization of ligand-gated ion channels. Pharmacol Rev. 2009; 61:98-114. | Article | PubMed Abstract | PubMed FullText

39. Popova E. ON-OFF Interactions in the Retina: Role of Glycine and GABA. Curr Neuropharmacol. 2014; 12:509-26. | Article | PubMed Abstract | PubMed FullText

40. Pearson P.M. The effects of ethyl alcohol on visual and auditory thresholds. Doctoral dissertation, University of Western Ontario, Canada. 1997.

41. Armstrong-Gold CE and Rieke F. Bandpass filtering at the rod to secondorder cell synapse in salamander (Ambystoma tigrinum) retina. $J$ Neurosci. 2003; 23:3796-806. | Article | PubMed

42. Pandarinath C, Victor JD and Nirenberg S. Symmetry breakdown in the ON and OFF pathways of the retina at night: functional implications. J Neurosci. 2010; 30:10006-14. | Article | PubMed Abstract | PubMed FullText

43. Ron D, Wang J. The NMDA Receptor and Alcohol Addiction. In: Van Dongen AM, editor. Biology of the NMDA Receptor. Boca Raton (FL): CRC Press. 2009.

44. Cordero SLA, Stab II BR, Guillen F and Montano EAR. A Molecular Mechanism of Ethanol Dependence: The Influence of the Ionotropic Glutamate Receptor Activated by N-Methyl-D-Aspartate. In: David Belin (ed). Addictions - From Pathophysiology to Treatment. CC BY 3.0 license. 2012.

45. Lima-Landman MT and Albuquerque EX. Ethanol potentiates and blocks NMDA-activated single-channel currents in rat hippocampal pyramidal cells. FEBS Lett. 1989; 247:61-7. | Article | PubMed

46. Masood K, Wu C, Brauneis U and Weight FF. Differential ethanol sensitivity of recombinant $\mathrm{N}$-methyl-D-aspartate receptor subunits. $\mathrm{Mol}$ Pharmacol. 1994; 45:324-9. | Article | PubMed

47. Mirshahi T and Woodward JJ. Ethanol sensitivity of heteromeric NMDA receptors: effects of subunit assembly, glycine and NMDAR1 $\mathbf{M g}(2+)-$ insensitive mutants. Neuropharmacology. 1995; 34:347-55. | Article | PubMed

48. Peoples RW, White G, Lovinger DM and Weight FF. Ethanol inhibition of N-methyl-D-aspartate-activated current in mouse hippocampal neurones: whole-cell patch-clamp analysis. Br J Pharmacol. 1997; 122:1035-42. | Article | PubMed Abstract | PubMed FullText
49. Calton JL, Wilson WA and Moore SD. Reduction of voltage-dependent currents by ethanol contributes to inhibition of NMDA receptormediated excitatory synaptic transmission. Brain Res. 1999; 816:142-8. | Article | PubMed

50. Criswell HE, Ming Z, Pleasant N, Griffith BL, Mueller RA and Breese GR. Macrokinetic analysis of blockade of NMDA-gated currents by substituted alcohols, alkanes and ethers. Brain Res. 2004; 1015:107-13. | Article | PubMed

\section{Citation:}

Kuzeva A, Panev S, Zhekova D, Kupenova P and Popova E. Opposite effects of ethanol on electroretinographic $\mathrm{ON}$ and $\mathrm{OFF}$ responses are due to its action in the distal retina. J Psychiatry Brain Funct. 2015; 2:6. http://dx.doi.org/10.7243/2055-3447-2-6 